\title{
An Empirical Study on Sales Performance Effect and Pricing Strategy for E-Commerce: From the Perspective of Mobile Information
}

\author{
Chia-Huei Wu, ${ }^{1}$ Zichun Yan $\mathbb{D D}^{2}{ }^{2}$ Sang-Bing Tsai $\left(\mathbb{D},{ }^{3,4}\right.$ Weinan Wang, ${ }^{5,6}$ Boshu Cao, ${ }^{7}$ \\ and $\mathrm{Xin} \mathrm{Li}^{2}$ \\ ${ }^{1}$ Institute of Service Industries and Management, Minghsin University of Science and Technology, Hsinchu 304, Taiwan \\ ${ }^{2}$ Economics and Management College, Civil Aviation University of China, Tianjin 300300, China \\ ${ }^{3}$ Regional Green Economy Development Research Center, School of Business, WUYI University, Wuyishan 354300, China \\ ${ }^{4}$ Research Center for Environment and Sustainable Development of China Civil Aviation, Civil Aviation University of China, \\ Tianjin 300300, China \\ ${ }^{5}$ School of Economics and Management, Tsinghua University, Beijing 100084, China \\ ${ }^{6}$ Reasearch Center for Technological Innovation, Tsinghua University, Beijing 100084, China \\ ${ }^{7}$ Flight Technology College, Civil Aviation University of China, Tianjin 300300, China
}

Correspondence should be addressed to Zichun Yan; xmairline@126.com and Sang-Bing Tsai; sangbing@hotmail.com

Received 1 October 2019; Revised 27 January 2020; Accepted 20 February 2020; Published 23 June 2020

Academic Editor: Luca Bedogni

Copyright $\odot 2020$ Chia-Huei Wu et al. This is an open access article distributed under the Creative Commons Attribution License, which permits unrestricted use, distribution, and reproduction in any medium, provided the original work is properly cited.

The emergence of Internet product sales platform has not only greatly enriched consumers' choices and facilitated their purchasing behavior but also provided space for counterfeit products and relevant fraudulent signal strategies in China, which damage the consumer's rights and interests and further disrupt the normal order of the e-commerce market. However, effective empirical study on the long-term and dynamic influence mechanism of fraudulent signals of counterfeit products and the seller incentive mechanism is still unavailable in academic circles, especially in the Chinese market, where government regulation is deemed to be lacking. For the purpose of this paper, an empirical study has been conducted by virtue of Internet e-commerce platform data based on data capture technology to analyze the dynamic performance effect mechanism of e-commerce fraudulent signals of counterfeit products under multiple game conditions. The study results show that selling of counterfeit products by using fraudulent signals can improve the current sales performance, but it will cause a long-term performance decline consequently. Additionally, from the perspective of the pricing mechanism, this paper analyzes the said seller incentive mechanism of counterfeit products. Finally, this paper puts forward relevant management suggestions based on the empirical study findings.

\section{Introduction}

In the context of booming Internet technology and platform economy, Internet e-commerce as a new model has played the most important role in the new retail sector. The Internet e-commerce platform provides sellers and consumers with more convenient and cheaper means to facilitate information sharing and matchmaking tradeoff. Platform-based economy and e-commerce have become the fastest growing and most dynamic economic sectors in China and even the world. However, the e-commerce platform signal mechanism also has limitations. Usually, the online trading parties have no social network or acquaintance of offline trading. Consumers often need to determine the purchase behavior only based on limited product signals, e.g., product model, price, after-sale service, and quality, which are unilaterally disclosed by sellers. Moreover, the online purchase behavior has saved a lot of purchase time, so the time for a single trading is short, and the consumer often has no time to carefully distinguish fraudulent signals and real signals [1]. 
The above phenomena have led to higher possibility of performance improvement caused by fraudulent signals such as counterfeiting behaviors of e-commerce platform sellers, and the sales fraud of e-commerce platforms is more subtle usually [2]. Especially in China, more and more consumers choose online shopping on e-commerce platform. This trend has led the "copycat" culture. The word "copycat" was originally used to describe the imitation of previously monopolized products. Compared to the genuine products, these products can now be mass produced at a low cost. The "copycat" culture leads to more and more counterfeit products in the e-commerce platform. For example, Taobao, a subsidiary of Alibaba Group, the Chinese largest e-commerce platform listed on New York Stock Exchange in 2014, has seen a large number of counterfeit products with similar names and pictures, where some shops sell counterfeit products with fraudulent signals.

Counterfeit products can be defined as reproductions which appear similar to some genuine products in appearance [3]. The similar packaging, labeling, and trademarks may give fraudulent signal to consumers. However, do fraudulent signals given by fraudulent signals of counterfeit products have a significant improvement effect on the sales performance? Is the improvement effect durable? What is the driving mechanism of the seller using fraudulent signals? The solutions to these questions have a great practical significance for the healthy development of e-commerce and the construction of a positive e-commerce environment.

In the world, the $\mathrm{B} 2 \mathrm{~B}$ e-commerce exporting portals serving numerous sellers from different countries offer homogeneous or highly similar products. However, in the field of academic study, relevant signal theories in the e-commerce study usually focus on the effects of positive evaluation mechanisms such as platform reputation evaluation [4], while the study on fraudulent signals is limited to short-term effects. There is less effective study on dynamic influence mechanism of fraudulent signals and the seller's motivation thereof yet [4]. Therefore, theoretically, the study on the Internet sales platform data should be conducted in depth on dynamic influence and driving mechanism of the above-mentioned fraudulent signals, filling the relevant study gaps of signal theory under Internet platform conditions.

Therefore, the authors collect and sort out the product and seller data disclosed on Taobao platform, specifically the data of 641 counterfeit products from 147 counterfeit products sellers and 1923 non-brand-copycats from 441 noncounterfeit products sellers in this paper, verify the dynamic influence of fraudulent signals of counterfeit products on product sales performance by regression analysis, and propose corresponding management suggestions on seller motivation and sale price difference.

\section{Theory and Study Hypotheses}

With the rapid development of Internet technology and increasingly fierce market competition, there is a close relationship between consumers' purchase choices and product brands, and the positive role of brands is increasingly prominent. Online shopping platforms, as a unique network group organization connecting the purchase choice channel between products and consumers, gradually become an important communication channel for the selling of online brand products, thus exerting a great influence on consumer purchase choices and product brand building.

In the trading process, e-commerce platforms make buyers and sellers inconvenient to communicate with each other. Therefore, the possibility of trading largely depends on the seller's reputation and the mutual trust of both sides $[5,6]$. In this case, the third-party trading portal plays a key role in developing the clear product quality signaling means and promoting the buyers and sellers to trade on the web portal. Generally, the penalties on illegal behaviors and commercial frauds protect the interests of consumers and enterprises well in highly regulated markets; however, "hypnotized" by this trust-centered institutional logic, the buyer lacks the awareness and ability to identify misleading or fraudulent signals $[7,8]$. The buyers in a highly regulated country lack the awareness and ability to identify misleading or fraudulent signals; due to legal protection, these buyers tend to follow a trust-centered institutional logic and may easily trust the sellers in cyberspace. When there are few e-commerce platforms, buyers pay attention to the seller's factory or supply source to ensure manufacturing qualification and product quality. However, buyers turn to other cheaper signals to check the reliability of the seller and its products as more and more e-commerce platforms emerge [9].

Fraudulent signals entice potential buyers to believe that top sellers are the best. Psychologically, as determined by humanity, online buyers prefer sellers and products at the top and bottom of the screen due to the convenience of information access [10]. In contrast, viewing the seller's organic information by scrolling down, flipping, and clicking on the e-commerce platform will waste time and consume the patience of buyer, and many sellers offer similar or highly similar products on the e-commerce platform $[4,11,12]$. On one hand, the fraudulent signals of counterfeit products can easily take advantage of the buyer's psychological weakness; on the other hand, search engines that push counterfeit products ads to interested buyers impose an influence on sales performance. Therefore, the following hypothesis is proposed in this paper.

Hypothesis 1. The fraudulent signals of counterfeit products can improve the performance level of sellers in the current period.

In an online shopping process with new shopping environment and manner, the buyers obtain the information of the product, the service, and the seller/service provider mostly through website. For buyers on e-commerce platforms, it takes time to distribute the products they purchase to the channels and end customers, and it will take more time to accept feedback from end customers and reexamine/ reconfigure their purchase strategies. As a result, there is a time delay from purchasing a product to finding quality problems and changing the supplier, which gives the seller 
an opportunity to exploit fraudulent signals. The fraudulent signals camouflage the nature of sponsor's ads, so they have a stronger influence on the seller's sales. These signals may dynamically reflect the reputation of product and seller, because new reviews, scores, and trading information will be input and displayed on the trading portal's web page. As a result, the sellers with good organic signals may ultimately benefit from their reputation premiums and achieve sustained performance growth $[13,14]$. Signal receivers react negatively to inaccurate signals, which often results in punitive consequences. Unconstrained buyers may offer unfavorable rating scores to the former sellers on website and then turn to the sellers with more reliable organic signals. Therefore, the product quality and seller reputation reflected in organic signals will be the ultimate determinant factor of the good performance of an enterprise in the long run. Based on this, the following hypothesis is proposed in this paper.

Hypothesis 2. The fraudulent signal of counterfeit products can lower the performance level of sellers in the next period.

On e-commerce platforms, due to the nature of information asymmetry, buyers and sellers do not communicate face-to-face before conducting trading, nor could they verify the quality of products [15]. In this case, sponsor search ads with obvious inducing signals, such as banner ads and those with incentive ads or sponsorship tags, can effectively convince potential buyers. The attractive design and easy access of such inducing signals will have a certain influence on the purchase intention of some buyers. Usually, the price and conversion rate of top search results tend to be higher [14]. If the e-commerce platform pays for the cost of this part, the investment for search ads can induce the consumer's purchase choices, making the consumer believe that the product quality is better than the competitors', so that the website click conversion rate may be higher than the seller's [4]. In this case, companies adopting sponsor search ads will dynamically adjust prices to compensate for ad costs and need additional costs for the marketing of counterfeit products of website [16]. Based on this, the following hypothesis is proposed in this paper.

Hypothesis 3. Counterfeit products have a higher selling price.

Whether a consumer purchases a product depends on the value perceived by the consumer, that is, the relationship between the benefit obtained from the product desired and its price. The greater the perceived benefit, the greater the perceived value of the consumer. Especially in the process of online consumption, the greater the consumer's perceived benefit from counterfeit products, the greater the possibility of purchase. In an online shopping environment, consumers obtain products and relevant information through network and other channels. During information gathering, consumers collect and query product information, learn about the performance and quality of products, and experience the service level of the enterprise through online consultation and communication, thus forming the perception of benefits such as product quality, utility, and service.
Online sale of counterfeit products has broken through the limitations of time and space to a certain extent, enabling buyers to obtain corresponding economic utilities and perceived benefits, thereby facilitating consumers' purchase decisions on counterfeit products on e-commerce platforms and increasing product sales performance. The following factors will affect consumers' perceived benefits and further affect their perceived value: (1) whether consumers are satisfied with all indicators of online purchased products, (2) whether interface design of shopping website is friendly, (3) whether product information is comprehensive, detailed, and conducive to search and query, and (4) the attitudes of customer service and after-sale service and the feedback timeliness. Therefore, the higher the perceived value provided by the e-commerce platform for the consumer during online shopping, the better the sales performance; however, the friendly shopping website design and the high-quality and timely sales service require certain costs, and some of the costs are also added to counterfeit products sold on e-commerce platforms. Based on the above analysis, the following hypothesis is proposed.

Hypothesis 4. The higher the product price, the lower the promotion effect on the sales performance by fraudulent signal of the counterfeit products in the current period.

For the counterfeit products in the current fraudulent signal, raising the price of products will weaken the improvement of sales performance.

In addition to perceived benefits and monetary costs, consumers also have to bear perceived risks due to the uncertainty about the results and consequences of purchase decisions [17]. Risk represents an uncertain cost or encounter in the future. Risk cost will have a stronger influence on consumer behaviors, and the perceived risk will affect the purchase intentions through the overall assessment of trading [18]. The consumer's decision to change, postpone, or cancel a purchase is largely influenced by the perceived risk, and each consumer will avoid the perceived risk to the maximum extent when making a purchase decision [19].

For e-commerce platforms, frequently repeated online tradings rely more on product quality rather than on search ranking or promotional ads available on the shopping website. When the repeated purchase behavior occurs, the consumer will have an increased profession level and learn about the product better, so as to get higher distinguish ability and make purchase decision more rationally. Compared with the purchase in current period, the blindness and impulsiveness of purchase motivation are greatly reduced. At present, the online comment systems of some e-commerce platforms have been relatively perfect, the timeliness of delivering comments has become increasingly stronger, and the contents of comments have become more and more referential [20]. The consumer, where having a negative choice of the product, will reduce the possibility of purchase decision or reduce the purchase of the related products of this company and even consider not choosing the related products of this company any more [21]. For consumers, it is attractive enough when the quality of counterfeit products is 
improved and the price is lower than that of quality products [22]. Therefore, the following hypothesis is proposed.

Hypothesis 5. The higher the product price, the higher the inhibition effect on the sales performance by fraudulent signal of the counterfeit products in the next period.

\section{Data Structure and Method}

Taobao, an Internet business platform in China, is selected as the data source for data mining in this paper. This e-commerce platform operates with Internet social media function. Taobao is selected as the sample data source in consideration: (1) Taobao, the fastest growing e-commerce platform in recent years, has nearly 500 million registered users, more than 120 million daily active users, and 1 billion online products in China; (2) during the expansion of Taobao, there were a lot of problems of counterfeit products and fraudulent models, which have been reported by the media for many times; and (3) Taobao uses the third-party payment tool "Alipay" to make consumers trust the tradings on Taobao. However, according to the disclosure by Chinese Consumer Association in 2016, there are still plenty of fraudulent behaviors on Taobao, which hinder and perplex consuming experiences. For example, some shops selling counterfeit products employ "so-called buyers" to conduct fictitious trading to improve their ranking and sales and attract customers with good reviews. Therefore, the fraudulent signal functions more effectively on this platform.

In summary, the data of 641 types of counterfeit products with similar names and images on Taobao, which come from six categories, that is, general merchandise, shoes and bags, food, electrical appliance, mother and baby products, and sports, from January 2018 to June 2018, is used in this paper. To conduct a control study, the non-brand-copycat and the non-brand-copycat seller control group are set up. According to the ratio $1: 3$ of counterfeit products to nonbrand-copycats in each category, 1923 non-brand-copycat pieces of information are grabbed in the same price range in this paper. The above products belong to 390 non-brandcopycat sellers who have never sold counterfeit products in the current month, so the information of the above sellers is grabbed in this paper. See Table 1 for the numbers of products and sellers. The above content is displayed on the homepage of the website and can be converted into structured data by means of data mining technology. Based on this, the cross-sectional database established by the 641 observed values was used for empirical analysis.

\section{Variable Design}

Regarding dependent variable, firm sales value, profits, market share, and market exit are widely adopted as measures of firm performance [23]. In the text mining process, only the data about sales value is obtained. According to the study of Deng and Wang [4], the product sales is used as a dependent variable in this paper. The seller's product sales can indicate the performance effect of its sales strategy. Whether the fraudulent signals of counterfeit products can affect sales is an important measure of the performance effect. So the sales in the current month and the next month of two kinds of sellers are adopted as sales variables in current and next period in this paper, and the log values of above two variables are taken to eliminate the data deviation [4]. To verify Hypothesis 3, the product price is used as a dependent variable to test the seller's fraudulent signal motive. According to the study of Deng and Wang, the product price is used as a variable to test whether the price of counterfeit products is significantly higher than that of nonbrand-copycat. Similarly, the log values of above price variables are also taken [4].

For explanatory variable, in this paper, the dummy variable counterfeit products are used to explain whether the fraudulent signal of counterfeiting significantly affects sales performance under dynamic conditions and whether it can improve product price. Two dummy variables of counterfeit products are generated in this paper: if a product is counterfeit, its dummy variable is set as 1 and 0 otherwise; if a seller has sold counterfeit products, its dummy variable is set as 1 and 0 otherwise.

For moderator variable, in order to verify the moderation proposed by Hypotheses 4 and 5, the average price of the seller's products sold in the current month is used as a moderator variable to test the seller's performance effect of fraudulent signal under different price conditions in this paper. Product price is measured by the logarithm of average product price weighted by each product's total sales of that seller [4].

For control variables, with the proliferation of online review systems on e-commerce portals, buyers tend to trust that online consumer review is a good proxy for overall word of mouth and may not be easily manipulated [24-28]. Control variables are added in this paper; for example, log value of historical seller sales data released on Taobao is used as a variable to control the seller's historical sales experience; number of comments on products and sellers can reflect consumers' evaluation on products and sellers, so the log values of above two variable are added in this paper; at the same time, log value of total number of people for product crowd ordering and log value of total seller crowd ordering number are also added in this paper; discount is also a factor affecting sales performance and price, so dummy variable on discount is added in this paper. Finally, dummy variables of time and seller's location are also added in this paper (see Table 2 for the variables and correlation coefficients).

\section{Results and Discussion}

Based on the above variables, PMS method is adopted to test the relevant hypotheses in this paper. PMS (propensity score matching), first proposed by Rubin and Rosenbaum in 1983, is the conditional probability of assigning any research object to the treatment group or control group given a set of covariables. PMS method is mainly applied to the study of two groups of data, and the results of multiple covariates can be expressed. PMS can control the selectivity bias by adjusting the covariate equilibrium between the treatment group and the control group. To verify Hypotheses 1 and 2, 
TABLE 1: Numbers of products and sellers.

\begin{tabular}{lcccc}
\hline & Counterfeit products & Noncounterfeit products & Counterfeit products seller & Noncounterfeit products seller \\
\hline General merchandise & 175 & 525 & 47 & 151 \\
Shoes and bags & 106 & 318 & 27 & 82 \\
Food & 108 & 324 & 15 & 44 \\
Electrical appliance & 79 & 237 & 19 & 53 \\
Mother and baby products & 86 & 258 & 18 & 56 \\
Sports & 87 & 261 & 147 & 390 \\
Total & 641 & 1923 & & 390 \\
Total number of products (2564) & & & & \\
Total number of sellers (537) & & & \\
\hline
\end{tabular}

TABLE 2: Variables and correlation coefficients.

\begin{tabular}{|c|c|c|c|c|c|c|c|c|c|c|c|c|}
\hline & 1 & 2 & 3 & 4 & 5 & 6 & 7 & 8 & 9 & 10 & 11 & 12 \\
\hline (1) Log value of sales in the current period & 1 & & & & & & & & & & & \\
\hline (2) Log value of sales in the next period & 0.330 & 1 & & & & & & & & & & \\
\hline (3) Product price log value & -0.069 & 0.029 & 1 & & & & & & & & & \\
\hline (4) Log value of seller price & -0.079 & 0.001 & 0.409 & 1 & & & & & & & & \\
\hline $\begin{array}{l}\text { (5) Dummy variable of counterfeit } \\
\text { products }\end{array}$ & 0.194 & 0.124 & -0.016 & 0.018 & 1 & & & & & & & \\
\hline $\begin{array}{l}\text { (6) Dummy variable of counterfeit } \\
\text { products seller }\end{array}$ & 0.232 & 0.142 & -0.001 & 0.029 & 0.398 & 1 & & & & & & \\
\hline (7) Log value of historical seller sales & 0.205 & 0.104 & -0.024 & -0.019 & 0.079 & 0.038 & 1 & & & & & \\
\hline $\begin{array}{l}\text { (8) Log value of average product } \\
\text { evaluation number }\end{array}$ & 0.648 & 0.243 & 0.045 & 0.032 & 0.060 & -0.029 & 0.109 & 1 & & & & \\
\hline (9) Log value of average seller evaluation & 0.027 & 0.050 & 0.007 & 0.110 & 0.005 & 0.025 & 0.009 & 0.349 & 1 & & & \\
\hline $\begin{array}{l}\text { (10) Log value of total number of people } \\
\text { for product crowd ordering }\end{array}$ & 0.074 & 0.028 & 0.030 & -0.041 & 0.006 & 0.021 & 0.018 & 0.070 & 0.001 & 1 & & \\
\hline $\begin{array}{l}\text { (11) Log value of total seller crowd } \\
\text { ordering number }\end{array}$ & 0.137 & 0.149 & 0.114 & -0.029 & 0.298 & 0.031 & 0.013 & 0.027 & 0.033 & 0.395 & 1 & \\
\hline (12) Dummy variable on discount or not & 0.115 & 0.060 & 0.024 & 0.033 & -0.001 & 0.001 & 0.023 & 0.036 & 0.115 & 0.020 & 0.001 & 1 \\
\hline Average & 11.596 & 11.239 & 3.749 & & 0.250 & 0.273 & 10.240 & 3.776 & 3.217 & 6.133 & 11.934 & 0.339 \\
\hline Standard deviation & 4.827 & 4.917 & 1.841 & & 0.716 & 0.709 & 2.299 & 2.091 & 1.996 & 2.077 & 5.088 & 0.559 \\
\hline
\end{tabular}

the current sales performance and next sales performance are used, respectively, as dependent variables, and the counterfeit consumer dummy variable is used as trend variable for PSM to distinguish treatment group and control group for regression analysis; then product price log value is used as dependent variable, and the counterfeit products dummy variable is used as trend variable for PSM to distinguish treatment group and control group for regression analysis, so as to test Hypothesis 3; finally, the median log value of seller price is used to group for PSM regression to test Hypotheses 4 and 5.

Before PSM regression, the data shall be subject to imbalance test first to determine whether the variables of the PSM model are significant; the insignificant regression results of $t$-test are removed in PSM regression. The specific regression results are shown in Table 3.

Then the variables passing through $t$-test are selected in this paper to match and obtain PSM results. The regression results are shown in Table 4. According to the PSM results, after the match, the counterfeit products seller has a significant improvement in the sales in the current period after using the fraudulent signal, and the difference between groups after the match is $0.028(\beta=0.001)$. The fraudulent signals of counterfeit goods have improved sales amount in the short term; thus Hypothesis 1 is verified. At the same time, in the PSM regression results with the next sales performance as the dependent variable, the difference between the total sample PSM groups has significant negative regression coefficient, indicating that the fraudulent signals of counterfeit goods have a restraining effect on the seller's performance in the long run. On one hand, it is because consumers having purchased counterfeit products understand that sellers use fraudulent signals to improve sales performance and no longer purchase the products or disclose their counterfeiting behavior on the platform to lower the reputation of sellers. On the other hand, the platform may punish the sellers to some degree. Thus Hypothesis 2 is verified.

Provided that price is used as dependent variable, counterfeit products have higher price influence. The conclusion that counterfeit products have increased the price while deceiving consumers and will bring more sales profits to sellers may be obtained. The motive for fraudulent signals of counterfeit products maybe comes down to higher price; thus Hypothesis 3 is verified. 
TABLE 3: Test results of PSM imbalance.

\begin{tabular}{|c|c|c|c|c|c|c|c|}
\hline & \multicolumn{3}{|c|}{$\begin{array}{l}\text { Current sales performance as } \\
\text { dependent variable }\end{array}$} & \multirow{2}{*}{$\begin{array}{c}\text { Product price log } \\
\text { value as dependent } \\
\text { variable }\end{array}$} & \multicolumn{3}{|c|}{$\begin{array}{l}\text { Next sales performance as } \\
\text { dependent variable }\end{array}$} \\
\hline & $\begin{array}{c}\text { Total } \\
\text { sample }\end{array}$ & $\begin{array}{l}\text { Low-price } \\
\text { sample }\end{array}$ & $\begin{array}{l}\text { High-price } \\
\text { sample }\end{array}$ & & $\begin{array}{c}\text { Total } \\
\text { sample }\end{array}$ & $\begin{array}{l}\text { Low-price } \\
\text { sample }\end{array}$ & $\begin{array}{l}\text { High- } \\
\text { price } \\
\text { sample }\end{array}$ \\
\hline Log value of seller price & $2.84^{* * *}$ & $2.90^{* * *}$ & & $3.36^{* * *}$ & $1.69^{*}$ & 1.65 & $1.99^{*}$ \\
\hline Log value of historical seller sales & $2.81^{* * *}$ & $3.03^{* * *}$ & $2.64^{* * *}$ & 0.63 & $2.48^{* * *}$ & $2.14^{* *}$ & $2.65^{* * *}$ \\
\hline $\begin{array}{l}\text { Log value of average product } \\
\text { evaluation number }\end{array}$ & 0.67 & 0.29 & 0.77 & $4.34^{* * *}$ & 0.85 & 0.26 & 0.77 \\
\hline Log value of average seller evaluation & $2.90^{* * *}$ & $2.26^{* *}$ & $2.99^{* *}$ & $1.75^{*}$ & $3.17^{* * *}$ & $3.08^{* * *}$ & $2.87^{* * *}$ \\
\hline $\begin{array}{l}\text { Log value of total number of people } \\
\text { for product crowd ordering }\end{array}$ & -1.50 & 0.19 & -0.95 & $4.21^{* * *}$ & -1.02 & -1.66 & -0.98 \\
\hline $\begin{array}{l}\text { Log value of total number of seller } \\
\text { crowd ordering }\end{array}$ & $5.01^{* * *}$ & $5.28^{* * *}$ & $4.94^{* * *}$ & $1.69^{*}$ & $6.00^{* * *}$ & $5.37^{* * *}$ & $6.22^{* * *}$ \\
\hline Dummy variable on discount or not & $1.79^{*}$ & 0.98 & $1.86^{*}$ & 1.03 & $1.97^{* *}$ & $1.69^{*}$ & $2.21^{* *}$ \\
\hline Area dummy variable & Controlled & Controlled & Controlled & Controlled & Controlled & Controlled & Controlled \\
\hline Time dummy variable & Controlled & Controlled & Controlled & Controlled & Controlled & Controlled & Controlled \\
\hline
\end{tabular}

Note. (1) $1: 1$ matching is adopted for the above test match; (2) ${ }^{*},{ }^{* *}$, and ${ }^{* * *}$ represent that $t$ statistic is significant under levels of $10 \%, 5 \%$, and $1 \%$, respectively.

TABLE 4: PSM regression results.

\begin{tabular}{|c|c|c|c|c|c|c|c|}
\hline & \multicolumn{3}{|c|}{$\begin{array}{l}\text { Current sales performance as } \\
\text { dependent variable }\end{array}$} & \multirow{2}{*}{$\begin{array}{c}\text { Product price log } \\
\text { value as dependent } \\
\text { variable }\end{array}$} & \multicolumn{3}{|c|}{$\begin{array}{l}\text { Next sales performance as } \\
\text { dependent variable }\end{array}$} \\
\hline & $\begin{array}{c}\text { Total } \\
\text { sample }\end{array}$ & $\begin{array}{l}\text { Low- } \\
\text { price } \\
\text { sample }\end{array}$ & $\begin{array}{l}\text { High- } \\
\text { price } \\
\text { sample }\end{array}$ & & $\begin{array}{c}\text { Total } \\
\text { sample }\end{array}$ & $\begin{array}{l}\text { Low- } \\
\text { price } \\
\text { sample }\end{array}$ & $\begin{array}{c}\text { High- } \\
\text { price } \\
\text { sample }\end{array}$ \\
\hline $\begin{array}{l}\text { Difference between groups before } \\
\text { propensity scoring }\end{array}$ & $\begin{array}{l}-0.008 \\
(0.033)\end{array}$ & $\begin{array}{c}0.001 \\
(0.006)\end{array}$ & $\begin{array}{l}0.020^{*} \\
(0.011)\end{array}$ & $\begin{array}{c}0.47^{* * *} \\
(0.29)\end{array}$ & $\begin{array}{c}-0.021^{*} \\
(0.011)\end{array}$ & $\begin{array}{c}-0.007^{*} \\
(0.002)\end{array}$ & $\begin{array}{c}-0.007^{*} \\
(0.002)\end{array}$ \\
\hline $\begin{array}{l}\text { Difference between groups after } \\
\text { propensity scoring (ATT) }\end{array}$ & $\begin{array}{c}0.028^{* * *} \\
(0.001)\end{array}$ & $\begin{array}{c}0.019^{* * *} \\
(0.003)\end{array}$ & $\begin{array}{c}0.049^{* * *} \\
(0.005)\end{array}$ & $\begin{array}{c}0.98^{* * *} \\
(0.59)\end{array}$ & $\begin{array}{l}-0.046^{* * *} \\
(0.002)\end{array}$ & $\begin{array}{l}-0.060^{* * *} \\
(0.001)\end{array}$ & $\begin{array}{c}-0.012^{* * *} \\
(0.002)\end{array}$ \\
\hline
\end{tabular}

From the perspective of moderation, when the current sales performance is used as dependent variable, the regression coefficients of different samples have significant positive influence. This proves Hypothesis 1 again; namely, the performance improvement effect of fraudulent signals in high-price samples is higher than that in low-price samples. The results pass $Z$ test [4]. Therefore, for buying high-price products, consumers tend to examine all kinds of signals more carefully and more likely to identify fraudulent signals, so the fraudulent signal of counterfeit products is less effective [5]. Hypothesis 4 is verified. Similarly, in the next sales performance group regression, the high-price group and low-price group regression coefficients are significantly negative; thus Hypothesis 2 is proved again. At the same time, the high-price group has higher regression coefficient and passes through the $Z$ test; this shows that, for high-price products, consumers who are deceived by fraudulent signals tend to lower the seller's evaluation or reputation through public comments; then the risk reduction of interperiod performance of high-price product consumers using fraudulent signals of counterfeit products is greater; thus Hypothesis 5 is verified.

For the robustness test in this study, OLS regression is used to replace PSM regression first, and the dummy variables, counterfeit consumers, and counterfeit products are used as explanatory variables to analyze their influence on current sales performance, next sales performance, and product price product price log value, respectively. The regression results verify the conclusions of PSM regression.

\section{Conclusion}

6.1. Study Conclusions. Based on the regression analysis on the data related to the counterfeit products sold on Taobao, this study presents the interperiod dynamic performance influence mechanism of the above fraudulent signals of fraudulent signals of counterfeit goods, conducts the analysis on the price-based motive of sellers using the fraudulent signals of counterfeit goods, and probes the related moderation effect. The study includes the following conclusions:

(1) Fraudulent signals of counterfeit products can contribute to positive performance results in the current period, but, in the long run, they will restrain the seller's sales performance, thus going against the seller's long-term development.

(2) The price of counterfeit products is higher than that of similar products; in the short term, counterfeit products can bring higher profits to sellers. 
Therefore, the sellers will use fraudulent signals of counterfeit products for short-term benefits.

(3) Pricing will affect the role of fraudulent signals of counterfeit goods. For high-price products, consumers will be more cautious to review the signals given in product display; thus they are less likely to be deceived by counterfeit products. Once a consumer is deceived, consumers who purchase the higher-price products are likely to not trust the seller anymore and will give negative reviews on the platform, reducing the seller's reputation.

6.2. Strategic Suggestions. Online shopping has developed to a new type of trading channel as Internet technology booms. It comes with the new trading environment and mode significantly different from these of traditional trading channels. With the continuous development of e-commerce sector, more and more consumers do shopping via the Internet. Therefore, the study on the performance and pricing strategy of Internet counterfeiting behavior has important practical significance and enlightenment on how to improve the shopping environment of Internet platform and enhance consumers' willingness to purchase in China, especially after the promulgation of Electronic Commerce Law of the People's Republic of China in August, 2018. The law strictly restricts and regulates e-commerce sellers and deals by imposing levy and lifting market entry threshold, which can weaken the counterfeit product signaling effect and promotes the regulation and standardization on e-commerce platforms.

(1) In terms of optimizing the e-commerce environment, it is necessary to build a fine shopping environment for online shopping platforms, encourage companies to establish good images, and reduce the perceived risk of consumer in Internet shopping. Especially with the increasing popularity of mobile Internet technology, online shopping platform APPs make online transactions more convenient and efficient. More and More online shopping platform APPs tend to develop functions such as instant information sharing and product reviews by buyers, so that consumers can make decisions in purchasing. The social and interactive functions of network are made good use of to avoid fraudulent behavior caused by information asymmetry in online shopping, weaken the role of fraudulent signals, correctly guide the consumer's purchase decision, and reduce the purchase cost of consumer. These measures will make long-term positive influence on cultivating fine online consumer markets and promoting the e-commerce development.

(2) In e-commerce platform, perceived value and benefit are the key basis for consumers to make purchase decisions, while quality and function of products are an important basis for consumers to make purchases. Effective and enough information is displayed to manifest the quality of products on the e-commerce platform, increasing the trust of consumers on online shopping and contributing to a good external environment for the harmonious development of Internet economy, especially in the era of mobile Internet, with the continuous development of technology, information sharing, and transmission at an incredible speed exponential diffusion. Therefore, compared with the traditional commerce model, the reputation of products on e-commerce platform is more important in the information age. For continuous development, the business platform must lay the emphasis on the quality of products sold.

(3) Even though the sellers operating on e-commerce platforms can achieve short-term performance improvement by employing counterfeiting strategy in a short time, they are bound to confront negative performance consequences in a long run. Therefore, they should be long-sighted in the development by establishing good reputation and ensuring better product or service quality. Also, the advantage of the policies and regulations shall be exerted in facilitating consumers, sellers, and e-commerce platforms to jointly form organic stakeholder groups and create convenient, rapid, and efficient Internet shopping and marketing environments.

(4) China has been playing an increasingly important role in the world's market. Many developing countries are also confronted with China's problems. For example, counterfeit products are also common in Africa and southeast Asia. Therefore, this research is of unique significance for the theoretical research of commercial development in developing countries. Furthermore, many counterfeit products in developing countries are copycat of the enterprises' products or brands created in developed countries. The study can sound the alarm for the enterprises running in these developed countries to face the challenges posed by the special business conditions in developing countries.

\section{Data Availability}

The data used to support the findings of this study are included within the article.

\section{Conflicts of Interest}

The authors declare that they have no conflicts of interest.

\section{Acknowledgments}

This work was supported by Major Social Science Project of Tianjin Education Commission (2019JWZD3) and Provincial and Municipal Co-construction Project Fund of Zhongshan City, Guangdong Province.

\section{References}

[1] T. Mavlanova, R. Benbunan-Fich, and G. Lang, "The role of external and internal signals in E-commerce," Decision Support Systems, vol. 87, pp. 59-68, 2016. 
[2] S. Román and P. J. Cuestas, "The perceptions of consumers regarding online retailers' ethics and their relationship with consumers' general Internet expertise and word of mouth: a preliminary analysis," Journal of Business Ethics, vol. 83, no. 4, pp. 641-656, 2008.

[3] I. Pentina, L. E. Pelton, and R. W. Hasty, "Performance implications of online entry timing by store-based retailers: a longitudinal investigation," Journal of Retailing, vol. 85, no. 2 , pp. 177-193, 2009.

[4] Z. Deng and Z. Wang, "Early-mover advantages at crossborder business-to-business E-commerce portals," Journal of Business Research, vol. 69, no. 12, pp. 6002-6011, 2016.

[5] A. R. Reuber and E. Fischer, "Signalling reputation in international online markets," Strategic Entrepreneurship Journal, vol. 3, no. 4, pp. 369-386, 2009.

[6] G. L. Urban, F. Sultan, and W. J. Qualls, "Placing trust at the center of your Internet strategy," Sloan Management Review, vol. 42, no. 1, pp. 39-48, 2000.

[7] D. D. Bergh, B. L. Connelly, D. J. Ketchen, and L. M. Shannon, "Signalling theory and equilibrium in strategic management research: an assessment and a research agenda," Journal of Management Studies, vol. 51, no. 8, pp. 1334-1360, 2000.

[8] M. Spence, "Job market signaling," The Quarterly Journal of Economics, vol. 87, no. 3, pp. 355-374, 1973.

[9] A. R. Reuber and E. Fischer, "When nobody knows your name: country-of-origin as a reputational signal for online businesses," Corporate Reputation Review, vol. 14, no. 1, pp. 37-51, 2011.

[10] L. A. Granka, T. Joachims, and G. Gay, "Eye-tracking analysis of user behavior in WWW search," in Proceedings of the 27th Annual International ACM SIGIR Conference on Research and Development in Information Retrieval, pp. 478-479, Sheffield, UK, 2004.

[11] I. Clarke and T. B. Flaherty, "Web-based B2B portals," Industrial Marketing Management, vol. 32, no. 1, pp. 15-23, 2003.

[12] J. Zhao, S. Wang, and W. V. Huang, "A study of B2B e-market in China: E-commerce process perspective," Information \& Management, vol. 45, no. 4, pp. 242-248, 2008.

[13] A. Agarwal, K. Hosanagar, and M. D. Smith, "Do organic results help or hurt sponsored search performance?" Information Systems Research, vol. 26, no. 4, pp. 695-713, 2015.

[14] S. Yang and A. Ghose, "Analyzing the relationship between organic and sponsored search advertising: positive, negative, or zero interdependence?" Marketing Science, vol. 29, no. 4, pp. 602-623, 2010.

[15] S. Rao, K. B. Lee, B. Connelly, and D. Iyengar, "Return time leniency in online retail: a signaling theory perspective on buying outcomes," Decision Sciences, vol. 49, no. 2, pp. 275305, 2018.

[16] S. Ye, G. Aydin, and S. Hu, "Sponsored search marketing: dynamic pricing and advertising for an online retailer," Management Science, vol. 61, no. 6, pp. 1255-1274, 2015.

[17] S. Shim, M. A. Eastlick, S. L. Lotz, and P. Warrington, "An online prepurchase intentions model: the role of intention to search," Journal of Retailing, vol. 77, no. 3, pp. 397-416, 2001.

[18] C. Wood and M. Scheer, "Incorporating perceived risk into model of consumer deal assessment and purchase intent," Advances in Consumer Research, vol. 23, no. 1, pp. 399-404, 1996.

[19] V. W. Mitchell and P. Boustani, "A preliminary investigation into pre- and post-purchase risk perception and reduction," European Journal of Marketing, vol. 28, no. 1, pp. 56-71, 1994.
[20] D. Gomulya, K. Jin, P. Lee, and T. Pollock, "Crossed wires: endorsement signals and the effects pf IPO firm delistings on venture capitalists' reputations," Academy of Management Journal, vol. 62, no. 3, pp. 641-666, 2018.

[21] A. Parasuraman, L. L Berry, and V. A. Zeithaml, "Understanding customer experience of service," Sloan Management Review, vol. 32, no. 3, pp. 39-48, 1991.

[22] K. Wilcox, H. M. Kim, and S. Sen, "Why do consumers buy counterfeit luxury brands?" Journal of Marketing Research, vol. 46, no. 2, pp. 247-259, 2009.

[23] S. H. Ang, P. S. Cheng, E. A. C. Lim, and S. K. Tambyah, "Spot the difference: consumer responses towards counterfeits," The Journal of Consmer Marketing, vol. 18, no. 3, pp. 219-234, 2001.

[24] F. Zhu and X. Zhang, "Impact of online consumer reviews on sales: the moderating role of product and consumer characteristics," Journal of Marketing, vol. 74, no. 2, pp. 133-148, 2010.

[25] S. Ivanaj, G.-B. Nganmini, and A. Antoine, "Measuring E-learners' perceptions of service quality," Journal of Organizational and End User Computing, vol. 31, no. 2, pp. 83-104, 2019.

[26] C.-L. Wei and C.-T. Ho, "Exploring signaling roles of service providers' reputation and competence in influencing perceptions of service quality and outsourcing intentions," Journal of Organizational and End User Computing, vol. 31, no. 1, pp. 86-109, 2019.

[27] L. Fabisiak, "Web service usability analysis based on user preferences," Journal of Organizational and End User Computing, vol. 30, no. 4, pp. 1-13, 2018.

[28] G. Khatwani and P. R. Srivastava, "Impact of information technology on information search channel selection for consumers," Journal of Organizational and End User Computing, vol. 30, no. 3, pp. 63-80, 2018. 